\title{
Advanced endoscopic submucosal dissection with magnetic bead-assisted traction based on gravity for a flat colorectal neoplasm with severe fibrosis
}

Endoscopic submucosal dissection (ESD) of colorectal lesions with severe submucosal fibrosis remains challenging. Fibrosis has also been implicated as a factor that increases the risk of incomplete or complicated dissection [1-3]. Several traction techniques have been described but remain to be established [4,5].

Traction by gravity seems to be one of the most useful methods for colorectal ESD [5]. We therefore devised a new gravity-based traction tool. This technique uses magnetic beads ( $\boldsymbol{F}$ Fig. 1 a) to apply traction. The weight can easily be adjusted by using an additional magnetic bead and the direction of traction by changing the patient's position. Magnetic bead-assisted ESD (MBA-ESD) is able to improve the field of vision, increase resection efficiency, and reduce risks of perforation and of cutting into lesions, as well as shortening the treatment time and lowering the costs.

A 55-year-old man with a flat neoplasm with a central ulcer scar $(15 \times 10 \mathrm{~mm})$ in the descending colon ( $\mathbf{F i g .} \mathbf{1} \mathbf{b}$ ) was admitted to our hospital to undergo colorectal ESD. Endoscopic mucosal resection had failed at another hospital owing to incomplete lifting of the lesion.

After a mixed glycerol-sodium-hyaluronate solution with diluted epinephrine and indigo carmine had been injected into the submucosal layer, an incision was made using a Dual-Knife. Difficulties arose immediately after we started the dissection because of severe submucosal fibrosis. Despite repeated injections, no lifting could be achieved and the submucosal layer could not be precisely exposed, with no accurate line of muscle layer evident.

Traction was successfully applied to the lesion by use of a magnetic bead that was fixed with the attached string to the edge of the mucosa using an endoclip ( $\triangleright$ Fig. 1 c). By changing the patient's position, traction could be further improved. A second magnetic bead was ad-

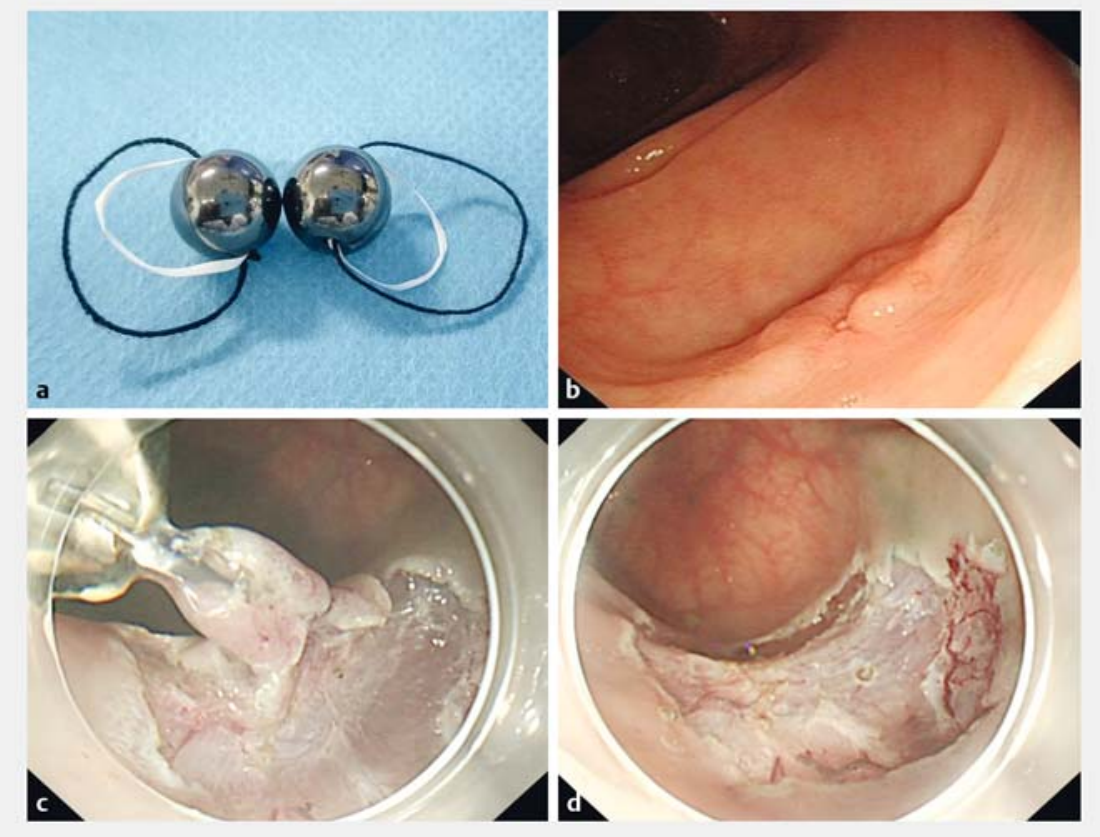

- Fig. 1 Magnetic bead-assisted endoscopic submucosal dissection. a The magnetic beads that are used to apply traction by gravity. $\mathbf{b}-\mathbf{d}$ Endoscopic views showing: $\mathbf{b}$ a flat adenoma with fibrosis in the descending colon; $\boldsymbol{c}$ the specimen being resected with magnetic beadassisted traction; $\mathbf{d}$ the ulcer bed after resection.

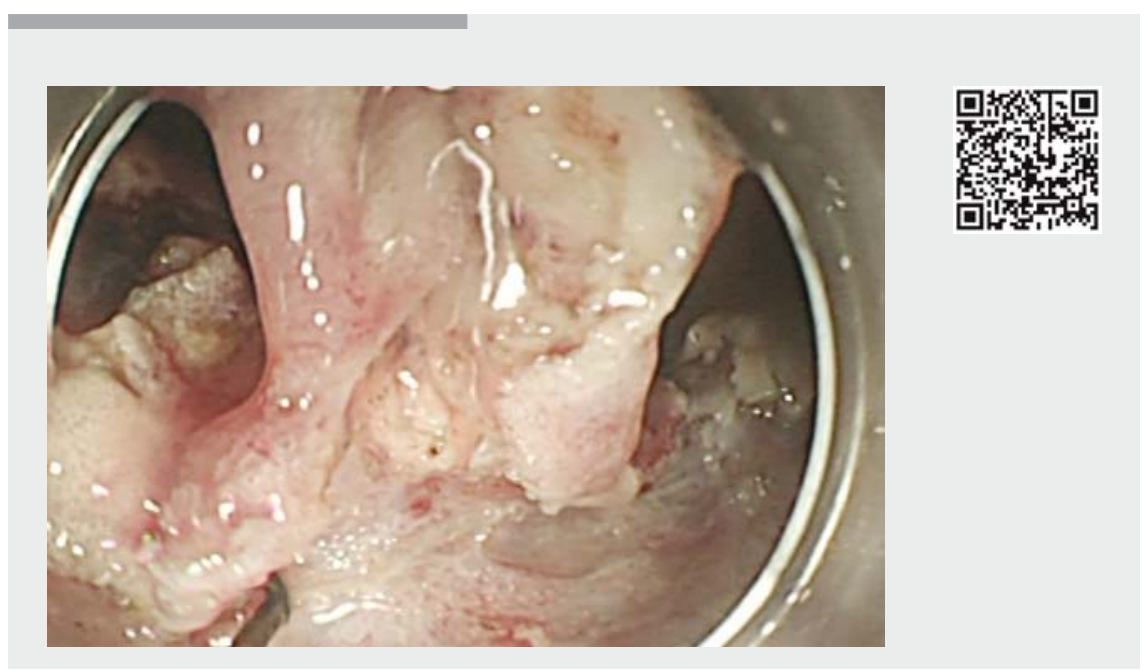

$\checkmark$ Video 1 Advanced endoscopic submucosal dissection with magnetic bead-assisted traction based on gravity for a flat colorectal neoplasm with severe fibrosis. 
ded to increase the weight and the strength of the traction. Thereafter, a precise cutting line was exposed so that careful dissection could be continued with the Hook-Knife. The lesion was completely resected en bloc with no complications (> Fig.1 d; V Video 1). Histological findings revealed a tubulovillous adenoma (R0) accompanied by extensive fibrosis.

Endoscopy_UCTN_Code_TTT_1AQ_2AD

\section{Competing interests}

None

The authors

Johannes Bethge ${ }^{1,{ }^{*}}$, Liansong Ye $\mathrm{e}^{2,}$, Mark Ellrichmann', Naveed Khan ${ }^{2}$, Zhe Feng ${ }^{2}$, Stefan Schreiber ${ }^{1}$, Bing $\mathrm{Hu}^{2}$

1 Department of Gastroenterology, University Medical Center Schleswig Holstein, Campus Kiel, Germany

2 Department of Gastroenterology, West China Hospital, Sichuan University, Chengdu, Sichuan, China

* These authors contributed equally to this work.
Corresponding author

\section{Bing Hu, MD}

No. 37, Guo Xue Alley, Wu Hou District, Chengdu City, Sichuan Province 610041, China

hubingnj@163.com

\section{References}

[1] Hayashi N, Tanaka S, Nishiyama S et al. Predictors of incomplete resection and perforation associated with endoscopic submucosal dissection for colorectal tumors. Gastrointest Endosc 2014; 79: 427-435

[2] Matsumoto A, Tanaka S, Oba S et al. Outcome of endoscopic submucosal dissection for colorectal tumors accompanied by fibrosis. Scand J Gastroenterol 2010; 45: 1329-1337

[3] Kim EK, Han DS, Ro Y et al. The submucosal fibrosis: what does it mean for colorectal endoscopic submucosal dissection? Intest Res 2016; 14: 358 - 364

[4] Imaeda H. Advanced endoscopic submucosal dissection with traction. World J Gastrointest Endosc 2014; 6: 286

[5] Lee BI. Debates on colorectal endoscopic submucosal dissection - traction for effective dissection: Gravity is enough. Clin Endosc 2013; 46: 467-471

\section{Bibliography}

DOI https://doi.org/10.1055/a-0624-2148

Published online: 12.6.2018

Endoscopy 2018; 50: 824-825

(c) Georg Thieme Verlag KG

Stuttgart · New York

ISSN 0013-726X

\section{ENDOSCOPY E-VIDEOS}

https://eref.thieme.de/e-videos

回回 Endoscopy E-Videos is a free ry access online section, reporting 靣触: on interesting cases and new

techniques in gastroenterological endoscopy. All papers include a high quality video and all contributions are freely accessible online.

This section has its own submission website at https://mc.manuscriptcentral.com/e-videos 